\title{
Treating Immunoglobulin A Vasculitis in an Elderly Patient Using Steroids: A Clinical Study
}

\author{
KOHEI ONO ${ }^{1,2}$, YOSHIHIRO FUKOE ${ }^{1}$, YUGEN LEE $^{1}$, MASAHIRO LEE $^{1}$, \\ MAKOTO WATANABE ${ }^{2}$, TAKESHI AOKI ${ }^{2}$ and MASAHIKO MURAKAMI ${ }^{2}$ \\ ${ }^{1}$ Department of Gastroenterological Surgery, Shiroyama Hospital, Gunma, Japan; \\ ${ }^{2}$ Department of Gastroenterological \& General Surgery School of Medicine, Showa University, Tokyo, Japan
}

\begin{abstract}
Herein, we report a case of immunoglobulin A vasculitis (IgAV) onset in an elderly patient. A 61-year-old male presented to our hospital with palpable purpura on his right leg and abdomen and diffuse abdominal pain. Computed tomography revealed thickened intestinal wall and ascites. In addition, his serum IgA and urinary protein levels were elevated. The histopathological finding of palpable purpura indicated vasculitis, and he was diagnosed with IgAV. Accordingly, steroid therapy was initiated. Gradually, purpura and abdominal pain disappeared, and he was discharged on day 26 after admission. Although IgAV is common in children, only few cases have been reported in elderly. Thus, when examining patients, including elderly, with palpable purpura and abdominal pain, the possibility of IgAV should be considered.
\end{abstract}

\section{Case Report}

A 61-year-old male with facial paralysis was referred to a dermatology clinic for palpable purpura on the right leg and abdominal pain. He was diagnosed with vasculitis and was prescribed haemostatic and intestinal regulators; however, his symptoms persisted. Subsequently, he visited our hospital after 10 days of purpura onset.

On admission, his blood pressure was $161 / 100 \mathrm{mmHg}$, pulse rate was $90 \mathrm{bpm}$, body temperature was $36.8^{\circ} \mathrm{C}$ and oxygen saturation in room air was 98\%. Physical examination revealed palpable purpura on his right leg and abdomen and diffuse abdominal pain without any sign of

This article is freely accessible online.

Correspondence to: Kohei Ono, Department of Gastroenterological Surgery, Shiroyama Hospital, 1, Iiduka, Ota, Gunma, 373-0817, Japan. Tel: +81 276460311, Fax: +81 276480105, e-mail: cohey.o@med.showa-u.ac.jp

Key Words: IgA vasculitis, onset in elderly patient, steroid. peritoneal irritation (Figure 1). Abdominal computed tomography (CT) revealed thickening of the duodenal, jejunal and ileal wall and pelvic ascites (Figure 2). In addition, serum immunoglobulin A (IgA), serum complement 3 (C3) and urinary protein levels were 434 (reference: 110410) $\mathrm{mg} / \mathrm{dl}, 137$ (reference: 80-140) $\mathrm{mg} / \mathrm{dl}$ and $264 \mathrm{mg} / \mathrm{day}$, respectively. Histopathologically, purpura on the leg exhibited perivascular neutrophilic infiltration in the top layer of the dermis, elevated nuclear-cytoplasmic ratio in the vascular endothelial cells and fibrinoid degeneration of the vessel wall (Figure 3). Based on these findings, he was diagnosed with IgA vasculitis (IgAV). Accordingly, he was immediately administered prednisolone sodium succinate (PSL); $1 \mathrm{mg} / \mathrm{kg} /$ day for a week intravenously. After 3 days, both the purpura and abdominal pain disappeared. A followup CT scan obtained on hospital day 7 revealed neither intestinal wall thickness nor ascites. Moreover, gastro endoscopy (hospital day 7) and colonic endoscopy (hospital day 9) revealed no significant findings. Thus, the PSL dose was gradually reduced by $10 \%$ a week. The patient initiated oral intake on day 11 and discharged on hospital day 26 without any symptoms. Five months after the onset, the patient was doing well without sequelae.

\section{Discussion}

IgAV, also known as Henoch-Schönlein purpura (HSP), is an immune complex small-vessel vasculitis. In patients of $\mathrm{IgAV}$, the immune complexes of IgA and $\mathrm{C} 3$ are deposited in capillaries, venules and arterioles (1). Although IgAV is common in children, only few cases have been reported in adults (3.4-14.3 cases per million) (2). Moreover, most adult patients diagnosed with IgAV exhibit symptoms similar to those exhibited by children with complete recovery from the disease (3).

Based on The American College of Rheumatology 1990 criteria, four criteria have been identified for IgAV: age $\leq 20$ years at disease onset; palpable purpura; acute abdominal pain and biopsy revealing granulocytes in the walls of small 

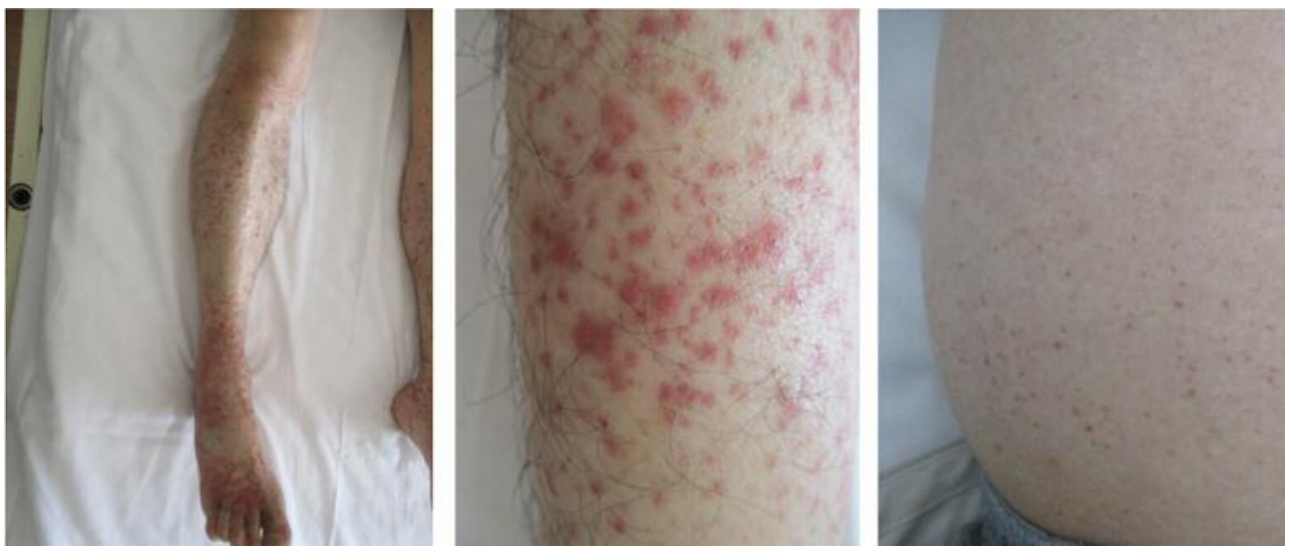

Figure 1. Palpable purpura on the right leg and abdomen of the patient.
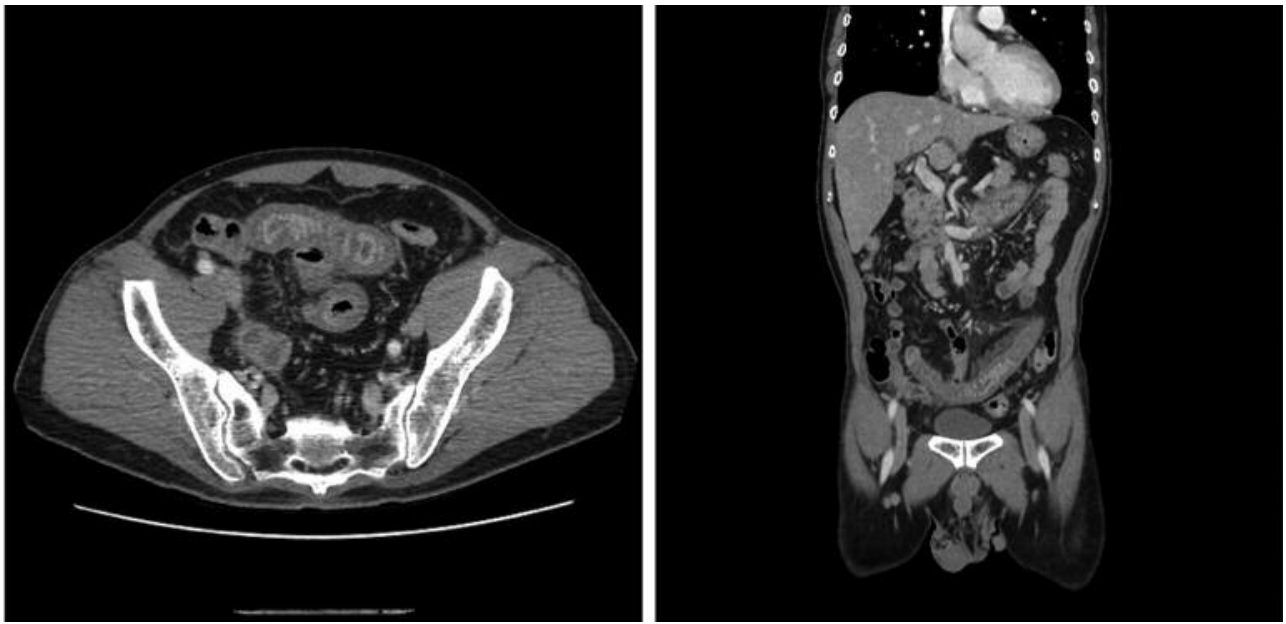

Figure 2. Abdominal computed tomography reveals thickening of the duodenal, jejunal and ileal wall and pelvic ascites.

arterioles or venules. The presence of more than two of these criteria distinguishes IgAV from other forms of vasculitis, with a sensitivity of $87.1 \%$ and a specificity of $87.7 \%$ (4). In addition, the European League Against Rheumatism also put forward the criteria in 2006. While the mandatory criterion was purpura or petechiae with lower limb predominance, the secondary criterion was the presence of one of the following symptoms: diffuse abdominal pain with acute onset; histopathology showing leukocytoclastic vasculitis or proliferative glomerulonephritis with predominant $\operatorname{IgA}$ deposits, arthritis or acute-onset arthralgia and renal involvement in the form of proteinuria or haematuria (5).

Approximately $1 \%$ of all patients with HSP develop chronic kidney disease, with adults developing this more often than children (6). The current clinical practice guidelines and observational studies propose that patients with $\operatorname{IgA}$ nephropathy with urine protein-to-creatinine ratio of $>1$ face a moderate-to-high risk of progressive kidney function loss $(7,8)$.

Although resting is the most common treatment of $\mathrm{IgAV}$, hospitalisation and steroid therapy should be considered in cases with severe abdominal pain or severe renal insufficiency (1). Reportedly, rituximab can decrease the number of hospital admissions and the burden of oral steroid therapy in adultonset IgAV (9). Moreover, cyclosporine and factor XIII replacement are effective alternatives for treating IgAV (10).

In the present report, the patient was referred to our hospital with abdominal pain, palpable purpura with vasculitis and proteinuria. He was diagnosed with IgAV based on The American College of Rheumatology and European 


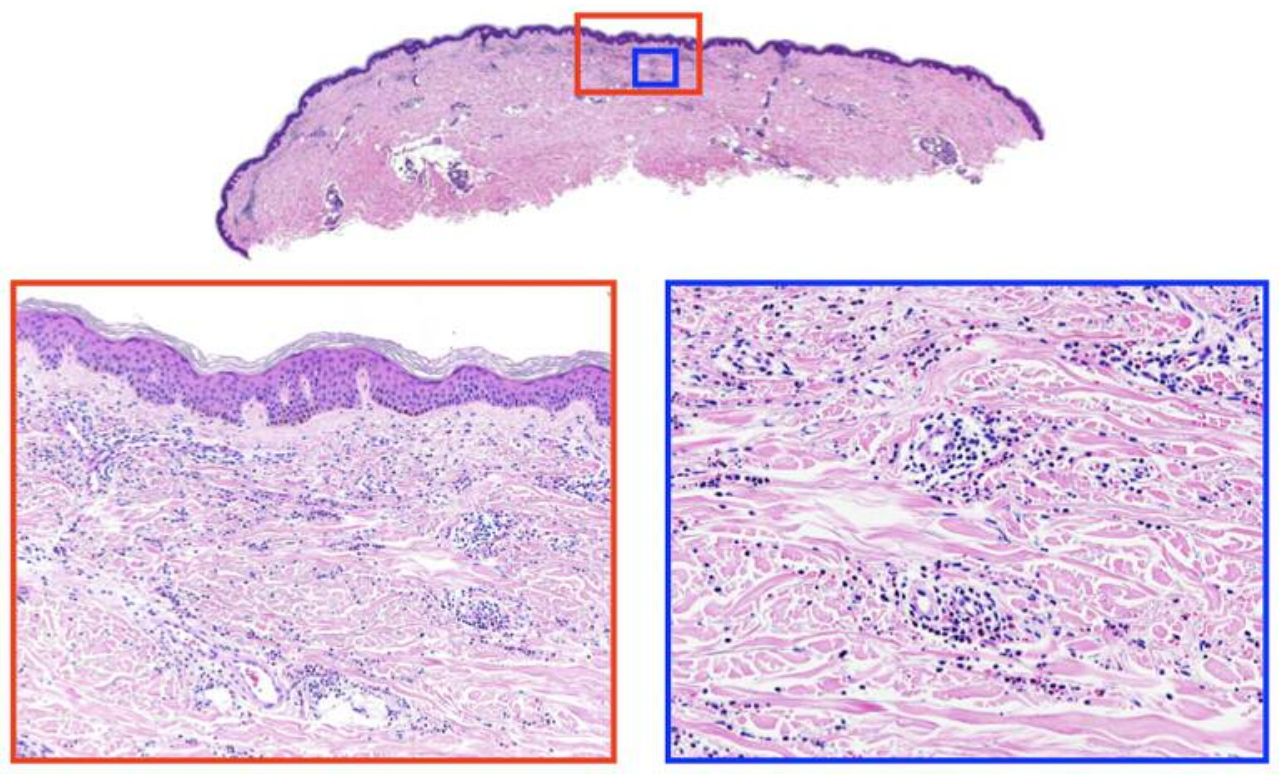

Figure 3. Perivascular neutrophilic infiltration in the top layer of the dermis, elevated nuclear-cytoplasmic ratio in vascular endothelial cells and fibrinoid degeneration of the vessel wall.

League Against Rheumatism criteria. As he exhibited symptoms different from those exhibited by children with $\mathrm{Ig} \mathrm{AV}$, the case was considered to be rare. Initiating PSL treatment drastically improved his symptoms, and he has been doing well 5 months after the onset, with no sequelae.

In conclusion, this report highlights that when examining elderly patients with palpable purpura and abdominal pain, the possibility of IgAV should be considered. To the best of our knowledge, limited reports exist on IgAV onset in the elderly. Therefore, this report could be critical to the accumulation of such cases.

\section{Conflicts of Interest}

The Authors have no conflicts of interest to declare regarding this study.

\section{Authors' Contributions}

KO acquired, analyzed, and interpreted the patient's clinical course and was a major contributor to the drafting of the manuscript. NO conceived, designed and critically revised the article. YF, YL, ML, MW and TA collected the clinical data from the patient and critically revised the article. MM supervised the study. All Authors read and approved the final manuscript.

\section{References}

1 McPartland K and Wright G: Acute abdominal pain: HenochSchönlein purpura case in a young adult, a rare but important diagnosis. Clin Med (Lond) 19(1): 77-79, 2019. PMID: 306512 52. DOI: 10.7861/clinmedicine.19-1-77

2 Watts RA and Scott DG: Epidemiology of the Vasculitides. Semin Respir Crit Care Med 25(5): 455-464, 2004. PMID: 16088491. DOI: $10.1055 / \mathrm{s}-2004-836139$

3 Blanco R, Martínez-Taboada VM, Rodríguez-Valverde V, García-Fuentes M and González-Gay MA: Henoch-Schönlein purpura in adulthood and childhood: two different expressions of the same syndrome. Arthritis Rheum 40(5): 859-864, 1997. PMID: 9153547. DOI: 10.1002/1529-0131(199705)40:5 <859:: AID-ART12>3.0.CO;2-J

4 Mills JA, Michel BA, Bloch DA, Calabrese LH, Hunder GG, Arend WP, Edworthy SM, Fauci AS, Leavitt RY and Lie JT: The American College of Rheumatology 1990 criteria for the classification of Henoch-Schönlein purpura. Arthritis Rheum 33(8): 1114-1121, 1990. PMID: 2202310. DOI: 10.1002/art. 1780330809

5 Ozen S, Pistorio A and Iusan SM: EULAR/PRINTO/PRES criteria for Henoch-Schönlein purpura, childhood polyarteritis nodosa, childhood Wegener granulomatosis and childhood Takayasu arteritis: Ankara 2008. Part II: final classification criteria. Ann Rheum Dis 69(5): 798-806, 2010. PMID: 20413 568. DOI: $10.1136 /$ ard 2009.116657

6 Srestha S, Sumingan N, Tan J, Alhous H, McWilliam L and Ballardie F: Henoch-Schönlein purpura with nephritis in adults: adverse prognostic indicators in a UK population. QJM 99(4): 253-265, 2006. PMID: 16565522. DOI: 10.1093/qjmed/hcl034

7 Rauen T, Eitner F, Fitzner C, Sommerer C, Zeier M, Otte B, Panzer U, Peters H, Benck U, Mertens PR, Kuhlmann U, Witzke O, Gross O, Vielhauer V, Mann JFE, Hilgers R and Floege J: Intensive supportive care plus immunosuppression in $\operatorname{IgA}$ nephropathy. N Engl J Med 373(23): 2225-2236, 2015. PMID: 26630142. DOI: 10.1056/NEJMoa1415463 
8 Kidney Disease: Improving Global Outcomes (KDIGO) Glomerulonephritis Work Group: KDIGO Clinical Practice Guideline for Glomerulonephritis. Kidney Int 2: 139-274, 2012. DOI: 10.1038/kisup.2012.12

9 Crayne CB, Eloseily E, Mannion ML, Azerf SP, Weiser P, Beukelman T, Stoll ML, Feig DI, Prescott Atkinson T and Cron RQ: Rituximab treatment for chronic steroid-dependent HenochSchonlein purpura: 8 cases and a review of the literature. Pediatr Rheumatol Online J 16(1): 71, 2018. PMID: 30428889. DOI: 10.1186/s12969-018-0285-2
10 Koshiba K, Muraoka S, Nanki $\mathrm{T}$ and Komatsumoto S: Successful treatment of IgA vasculitis complicated with bowel perforation and crescentic glomerulonephritis by combination therapy of glucocorticoid, cyclosporine and factor XIII replacement. Intern Med 57(20): 3035-3040, 2018. PMID: 29877285. DOI: 10.2169/ internalmedicine.0931-18

Received March 8, 2019

Revised April 22, 2019

Accepted April 23, 2019 